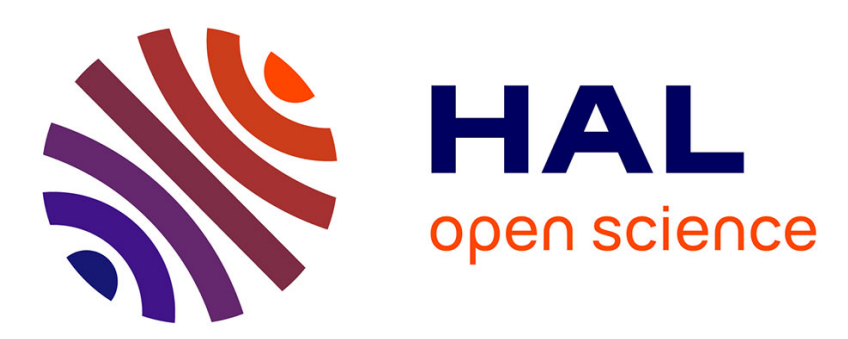

\title{
Analysis of laser shock waves and resulting surface deformations in an Al-Cu-Li aluminum alloy
}

Patrice Peyre, Laurent Berthe, Vincent Vignal, Ioana Popa, T. Baudin

\section{To cite this version:}

Patrice Peyre, Laurent Berthe, Vincent Vignal, Ioana Popa, T. Baudin. Analysis of laser shock waves and resulting surface deformations in an $\mathrm{Al}-\mathrm{Cu}-\mathrm{Li}$ aluminum alloy. Journal of Physics D: Applied Physics, 2012, 45 (33), pp.1-9. 10.1088/0022-3727/45/33/335304 . hal-02412964

\section{HAL Id: hal-02412964 https://hal.science/hal-02412964}

Submitted on 16 Dec 2019

HAL is a multi-disciplinary open access archive for the deposit and dissemination of scientific research documents, whether they are published or not. The documents may come from teaching and research institutions in France or abroad, or from public or private research centers.
L'archive ouverte pluridisciplinaire HAL, est destinée au dépôt et à la diffusion de documents scientifiques de niveau recherche, publiés ou non, émanant des établissements d'enseignement et de recherche français ou étrangers, des laboratoires publics ou privés. 


\title{
Analysis of laser shock waves and resulting surface deformations in an Al-Cu-Li aluminum alloy
}

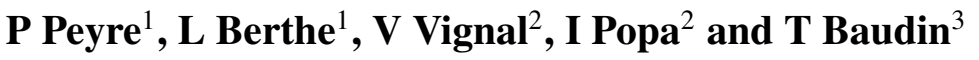 \\ ${ }^{1}$ PIMM, UMR 8006 CNRS-Arts et Métiers Paris-Tech, 75013 PARIS, France \\ 2 ICB, UMR 6303 CNRS-University of Burgundy, 21078 DIJON, France \\ ${ }^{3}$ ICMMO, UMR CNRS 8182, Université Paris XI, 91405 ORSAY, France \\ E-mail: patrice.peyre@ensam.eu
}

\begin{abstract}
Laser shock processing is now a recognized surface treatment for improving fatigue or corrosion behaviour of metallic materials through the generation of a compressive stress field. In turn, the analysis of shock wave propagation is of primary importance to predict numerically morphological and mechanical surface modifications.

Considering experimental and numerical analyses of shock wave propagation, and surface deformations induced by single impacts, a 2050 aluminum alloy having different microstructures was investigated under laser-shock loading. In a first step, the evolution of shock wave attenuation and elastic precursor amplitude was correctly reproduced by finite element simulations, and in a second step, surface deformations induced by 1-6 local impacts were also compared satisfactorily with experiments. This allowed us to validate mechanical loading and materials' constitutive law, but did not allow accurate determination of residual stress fields on a single impact.
\end{abstract}

(Some figures may appear in colour only in the online journal)

\section{Introduction}

Over the last 30 years, laser shock processing (LSP) has been proposed as a competitive alternative technology to classical surface treatments for improving fatigue, corrosion and wear resistance of metals. It has recently been developed as a practical process amenable to production engineering in aeronautical engines [1], or nuclear power plants [2]. This process aims at introducing a deep ( $\mathrm{mm}$ range) residual compressive stress field on metallic targets, through the generation of a laser-induced high-pressure plasma. More precisely, the process can be summarized as indicated in the following four-stage sequence: (1) laser pulses (in the $\mathrm{GW} \mathrm{cm}^{-2}$ range) impact the surface of a metal immersed in water (figure 1), and ablate a thin layer of the surface (less than $1 \mu \mathrm{m} / \mathrm{shot}$ ), (2) the vapour continues to absorb the remaining laser energy which ionizes into a high-pressure plasma, (3) due to the confining effect of water, the plasma pressure is amplified (up to several $\mathrm{GPa}$ ), and the resulting pressure discontinuity propagates into the material as a shock wave $[3,4]$, (4) the resulting heterogeneous plastic deformation of the metallic target imparts compressive stresses. Usually, the plasma confined regime allows maximum impact pressures of up to $5 \mathrm{GPa}$ in the $8-10 \mathrm{GW} \mathrm{cm}^{-2}$ intensity regime for $10-20 \mathrm{~ns}$ pulse duration, as experimentally shown in [4].

If we study the materials' behaviour under laser-shock loading, it has to be mentioned that laser shock waves (LSWs) can cause plastic deformation and compressive stresses, only when the plasma pressure is of sufficient magnitude to exceed the Hugoniot elastic limit (HEL) of the metal. Above $P=$ HEL, the specimen will undergo an extremely high strain rate (greater than $\left.10^{6} \mathrm{~s}^{-1}\right)$ during a short period of time $(\cong 10-20 \mathrm{~ns}$ in our case) and will be dynamically yielded. Consequently, the determination of HEL values is highly valuable to predict the plastic deformation induced by LSW. In previous works, elastic-plastic precursors, corresponding to HEL values, were determined using the VISAR velocimetry technique (figure 2), based on a Doppler modification of a probe 


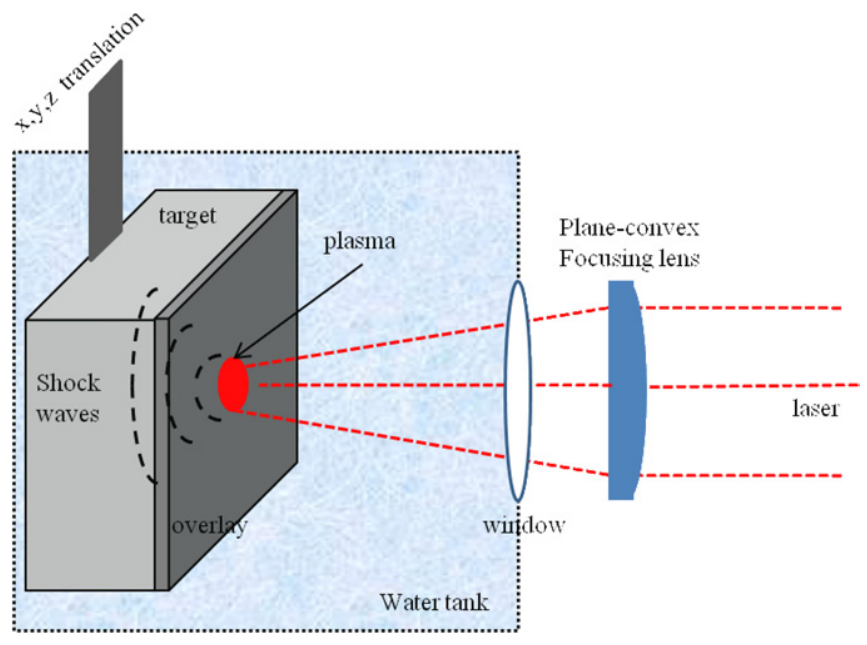

Figure 1. Generation of shock waves by a laser-induced plasma, experimental set-up.

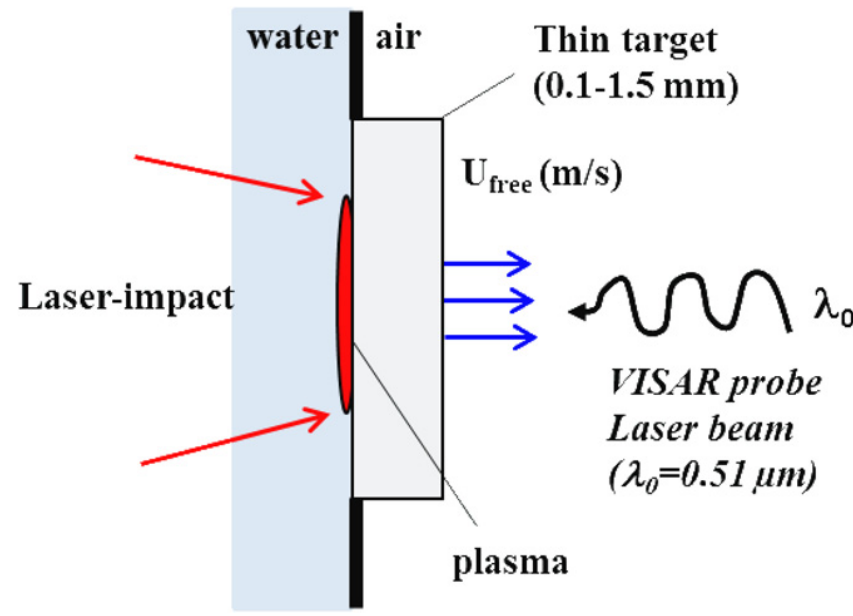

Figure 2. Configuration of the VISAR system [6] used for the analysis of laser-induced shock waves.

wavelength during the laser-induced acceleration of a thin foil [6].

To predict the residual stress field and optimize laser shock parameters, several experimental and analytical formulations have been reported in the literature, started by the early analytical work by Ballard [7]. The finite element method (FEM) was first introduced by Braisted and Brockman [8] to predict the residual stresses induced by LSP on carbon steels using the Abaqus software, and a combined explicit + implicit approach in 1999. From then on, several researchers have used Abaqus to analyse LSW propagation into different metal materials, and the resulting residual deformations and stresses [9-11]. Some of these simulations have shown a close match with experimentally measured residual stresses. Recent simplified approaches using the eigenstrain method have allowed the calculation of a large number of laser impacts in a reasonable amount of computation time [12].

Most of these numerical works have, in general, calculated average in-depth or surface stresses induced by LSP, without really considering materials' behaviour under laser-shock loading, without checking shock wave propagation, and without optimizing laser shock spatial and temporal loading. This paper aims at experimentally and numerically analysing single or multiple laser impacts on $\mathrm{Al}-\mathrm{Cu}-\mathrm{Li}$ in order to establish correlations between the laser pressure distribution $P=f(x, y, t)$, in-depth shock wave profiles $\Sigma=f(t, z)$ and the resulting surface deformations. Different microstructural states were used (T3, T8, T3 + friction-stir welding-FSW), in order to provide data on the influence of microstructures and associated mechanical properties versus laser shock-induced deformations and surface textures.

On the one hand, T3 and T8 conditions were chosen because these two thermal ageing treatments allowed generation of distinct precipitate microstructures whose strengthening effect is more or less pronounced, but without modification of the grain sizes. On the other hand, the severe dynamic recrystallization that occurs during a FSW (a new solid-state joining process) allowed generation of much smaller grain sizes in the nugget. The behaviour of a FSW nugget under laser-shock loading was also expected to be an interesting topic to address as a few recent studies have considered the ability of laser-shock peening to improve mechanical or corrosion resistance of FSW Al- $\mathrm{Zn}-\mathrm{Cu}-\mathrm{Mg}$ or $\mathrm{Al}-\mathrm{Cu}-\mathrm{Li}$ aluminum joints $[18,19]$.

\section{Experimental and numerical procedures}

\subsection{The $2050 \mathrm{Al}-\mathrm{Cu}-\mathrm{Li}$ alloy}

In aluminum alloys, the lithium simultaneously increases the elastic modulus and decreases the density. The material under investigation in this paper (AA 2050) is a third-generation $\mathrm{Al}-\mathrm{Cu}-\mathrm{Li}$ aluminum alloy developed by Alcan Aerospace, which is mainly composed of $3.5 \mathrm{Cu}, 0.9 \mathrm{Li}, 0.3 \mathrm{Mg}, 0.4$ $\mathrm{Mn}, 0.05 \mathrm{Fe}$ and Al-bal in wt\%. This material, recently developed for structural aerospace applications, exhibits a high specific resistance due to a dispersion strengthening effect by $\mathrm{Al}_{2} \mathrm{Cu} \mathrm{T} 1$ nanometric precipitates mostly located on the $\left\{\begin{array}{lll}1 & 1 & 1\end{array}\right\}$ planes of the aluminum matrix [13-17]. In this study, we have investigated the behaviour of three distinct microstructures of the 2050 alloy under laser-shock loading:

- A T8 near peak-aged condition (solution treatment, quenching and temper treatment at $155^{\circ} \mathrm{C}$ to promote hardening precipitate formation), provided in $15 \mathrm{~mm}$ thick plates, corresponding to a high elastic limit of $\sigma_{\mathrm{Y}}=$ $510 \mathrm{MPa}$. Prior to ageing, the alloy was stretched by a $2-3 \%$ value, in order to control the distribution and size of T1 hardening particles. Grain sizes ranging between $20 \mu \mathrm{m}$ and $500 \mu \mathrm{m}$ were identified by electron beam scattering diffraction (EBSD) analysis, with a texture orientated along the rolling direction, and local partially recrystallized areas.

- A T3 natural-ageing condition (tempering treatment at room temperature), provided in $10 \mathrm{~mm}$ thick plates, with a lower elastic limit $\left(\sigma_{\mathrm{Y}}=295 \mathrm{MPa}\right)$, but with a rather similar grain distribution as the T8 material.

- A friction-stir weld nugget T3 microstructure, with much smaller grain sizes $(5 \mu \mathrm{m})$ than the previous two microstructures (figure 3), and a preferential (10 1) orientation of grains. 


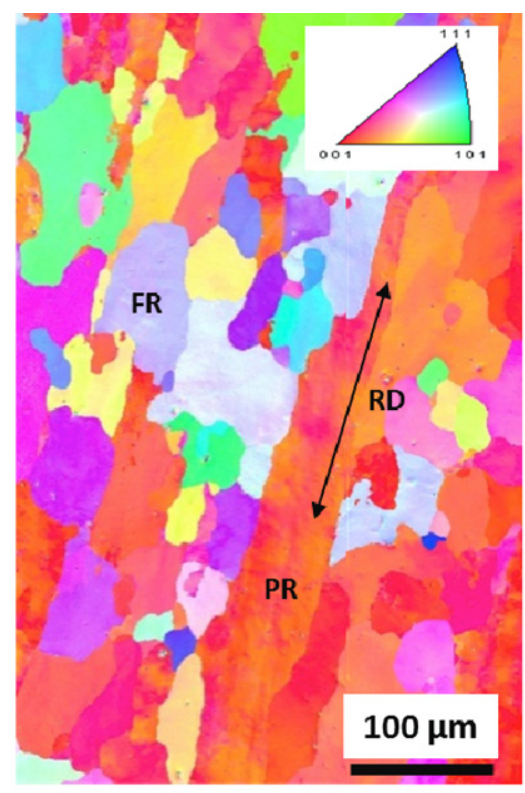

(a)

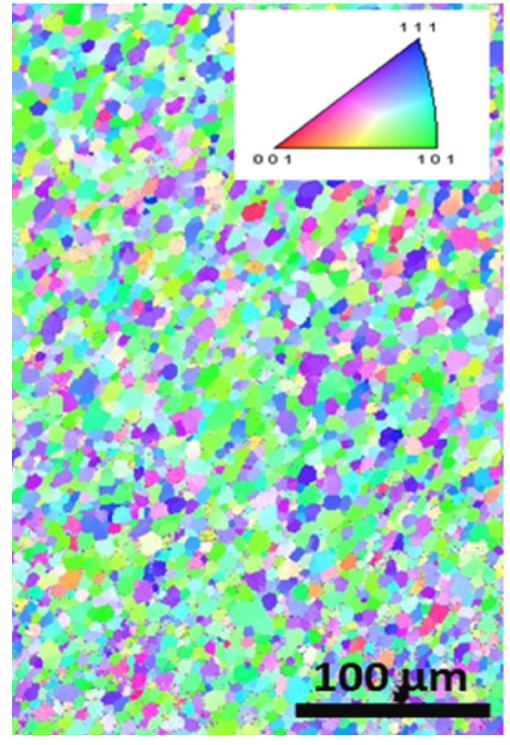

(b)

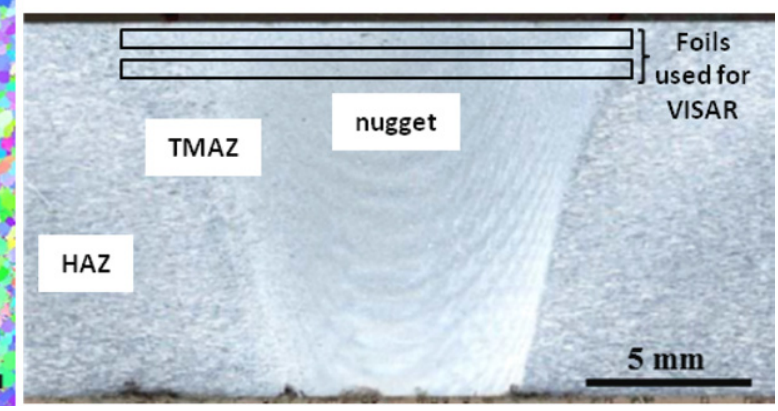

Figure 3. EBSD maps on (a) 2050-T8 (FR—fully recrystallized, PR—partially recrystallized, RD—rolling direction), (b) 2050-T3 FSW (EBSD surface view and cross-section), HAZ - heat affected zone, TMAZ - thermo-mechanically affected zone.

\subsection{Generation of laser impacts}

Laser impacts were generated with a Nd: YAG pulsed laser (Continuum Powerlite Plus), delivering $10 \mathrm{~ns}$ duration pulses with up to $1.5 \mathrm{~J}$ per pulse at $0.53 \mu \mathrm{m}$. The $0.53 \mu \mathrm{m}$ wavelength allows the use of deep water layers without generating extended laser light absorption. During LSP tests, the target was completely immersed in water $(5-10 \mathrm{~cm}$ thick), and a high pressure water nozzle was used to remove ablation dusts. Classically, 1-2 $\mathrm{mm}$ diameter impacts were used, with intensities in the $3-8 \mathrm{GW} \mathrm{cm}^{-2}$ range corresponding to estimated pressures between 2 and $5 \mathrm{GPa}$ using the empirical equation $P(\mathrm{GPa})=1.6 \cdot \sqrt{I\left(\mathrm{GW} \mathrm{cm}^{-2}\right)}$ [5]. The samples treated by overlapped impacts were coated with a $40 \mu \mathrm{m}$ aluminum adhesive, thick enough to avoid thermal effects on the target for a $10 \mathrm{~ns}$ laser pulse, but thin enough to limit pressure attenuation before transmitting shock waves to the 2050 target.

\subsection{VISAR analysis of impact pressures and elastic precursors}

The measurement of impact pressure and of the shock yield strength (HEL) were both carried out by VISAR (Velocity Interferometer System for Any Reflector) Doppler velocimetry. This technique was initially developed in the early 1970s [6], and has already been used successfully over the past 15 years $[5,20]$ for the investigation of laser-induced shock waves. It allows the analysis of shock wave propagation, by a simple measurement of back free surface velocities $U_{\text {Free }}$ $\left(\mathrm{m} \mathrm{s}^{-1}\right)$ behind laser-shock-accelerated thin foils, using the Doppler shift of a probe wavelength $\lambda_{0}$ (equation (1)). In turn, an estimation of in-depth shock wave $P=f(t, z)$ attenuation is possible using different foil thicknesses. In a second step, using Hugoniot conservation equations, we deduce particle velocities $U=U_{\text {free }} / 2$ (this approximation is correct when the shock unloads into air, which is true at the back 
Table 1. $\mu$ XRD conditions.

\begin{tabular}{lllllll}
\hline $\begin{array}{l}\lambda \alpha \\
(\mathrm{Cu})\end{array}$ & Filter & Collimator & $\begin{array}{l}\{\mathrm{hkl}\} \\
\text { planes }\end{array}$ & $\begin{array}{l}\Psi \\
\text { angles }\end{array}$ & $\begin{array}{l}\Psi \\
\text { Oscillations }\end{array}$ & $\begin{array}{l}\text { Acquisition } \\
\text { time (s) }\end{array}$ \\
\hline $1.709 \mathrm{~nm}$ & $\mathrm{~V}$ & $50 \mu \mathrm{m}$ & $\{311\}$ & 22 & \pm 5 & 100 \\
\hline
\end{tabular}

Table 2. 2D and 3D finite element models.

\begin{tabular}{llll}
\hline Model & Model size $(\mathrm{mm})$ & Number of elements & Element size (surface) \\
\hline 2D axisymmetry model & $6 \mathrm{~mm} \times(0.5-1) \mathrm{mm}$ & $280 \times 180=50400$ & $21 \mu \mathrm{m} \times(3-7 \mu \mathrm{m})$ \\
3D model & $7 \times 7 \times 3 \mathrm{~mm}^{3}$ & $80 \times 80 \times 70=448000$ & $88 \mu \mathrm{m} \times 88 \mu \mathrm{m} \times 10 \mu \mathrm{m}$ \\
\hline
\end{tabular}

surface of foils (figure 2)), and the corresponding maximum pressure (equation (2)) or HEL values (equation (3)). In our experimental set-up, a $0.53 \mu \mathrm{m}$ wavelength single mode probe laser, with a $0.4 \mathrm{~mm}$ diameter on the back free surface, was used to check the free velocity behind thin impacted foils:

$$
\begin{aligned}
& \lambda(t)=\lambda_{0} \cdot\left(1-\frac{2 U_{\text {Free }}(t)}{C_{\text {light }}}\right), \\
& P=\frac{1}{2} \rho \cdot D \cdot U_{\text {free }}+\frac{2}{3} \cdot \sigma_{\mathrm{Y}}=\frac{1}{2} \cdot \rho \cdot\left(C_{0}+S \cdot \frac{U_{\text {free }}}{2}\right) \\
& \cdot U_{\text {free }}+\frac{2}{3} \cdot \sigma_{\mathrm{Y}} \\
& \mathrm{HEL}=\frac{1}{2} \cdot \rho \cdot C_{\mathrm{el}} \cdot U_{\text {Free }}=\frac{1-v}{1-2 v} \cdot \sigma_{\mathrm{Y}}^{\mathrm{dyn}},
\end{aligned}
$$

where $U_{\mathrm{F}}$ is the back free velocity measured with VISAR $\left(\mathrm{m} \mathrm{s}^{-1}\right), \rho$ is the density $\left(\mathrm{kg} \mathrm{m}^{-3}\right), \quad S$ is the materials' constant ( $=1.38$ on aluminum), $C_{\mathrm{el}}$ is the elastic wave velocity $\left(=6100 \mathrm{~m} \mathrm{~s}^{-1}\right), C_{0}$ is the bulk sound velocity $\left(5400 \mathrm{~m} \mathrm{~s}^{-1}\right), v$ is the anisotropy coefficient $(=0.33$ on 2050$), \sigma_{\mathrm{Y}}^{\mathrm{dyn}}$ is the dynamic yield stress and $C_{\text {light }}$ is the velocity of light $\left(\approx 3 \times 10^{8} \mathrm{~m} \mathrm{~s}^{-1}\right)$.

\subsection{Experimental analysis of surface modifications}

The surface profiles were determined using a Veeco Dektak 150 stylus profilometer in order to measure deformations induced by single or multiple laser impacts. $2 \mathrm{D}$ and $3 \mathrm{D}$ profiles were displayed on surfaces submitted to 1-6 impacts at the same location.

The residual stresses were measured on a single laser impact using the well-known $\mathrm{x}$-ray diffraction, $\left\{\begin{array}{lll}1 & 1\end{array}\right\}$ as a diffracting plane, and a micro-X-ray diffraction ( $\mu$ XRD) device, allowing one to extend $\mathrm{x}$-ray examination to a microscopic level, using a $100 \mu \mathrm{m}$ diameter probe $\mathrm{x}$-ray beam. The measurements were realized at the Institut Carnot de Bourgogne (ICB) laboratory using a Brucker diffractometer with a $\mathrm{Cu}$ source, theta-theta geometry, Gobel mirror parallel optics and a 2D detector (table 1).

\subsection{The numerical model}

In most of the recent FEM analysis procedures of LSP [8-11], two distinct steps are considered to obtain an absolutely stable residual stress field: (1) a dynamic explicit analysis to investigate shock wave propagation and (2) a static analysis using an implicit algorithm to calculate residual stress fields. In our case, a single explicit dynamic calculation was selected to directly estimate a quasi-residual stress field, for a large number of impact loadings. Between each impact loading a $10^{-5} \mathrm{~s}$ time period allows recovering a near-zero kinetic energy equivalent to a quasi-static state. 2D axisymmetric and 3D finite element models were developed on the ABAQUS ${ }^{\mathrm{TM}} 6.9$ Explicit software to simulate the LSP process (table 2). In both cases, infinite elements were adopted as non-reflecting boundaries to avoid shock wave reflections on free surfaces.

The 2D model was mostly developed to simulate VISAR velocity signals on thin foils whereas surface deformations could be analysed by either $2 \mathrm{D}$ or 3D modelling. In the 3D model, the use of a BIAS geometrical function allowed a mesh refinement with element size $100 \mu \mathrm{m} \times 100 \mu \mathrm{m} \times 10 \mu \mathrm{m}$ near the impacted surface. Such thin surface elements are necessary to correctly consider the stress wave propagation (at $C_{0}$ speed) near the surface for a $\tau_{p} \approx 20 \mathrm{~ns}$ duration pressure pulse (figure 4(a)).

Like most of the previous papers, and due to the high strain rate involved during LSP events (near $10^{6} \mathrm{~s}^{-1}$ ), an equation of state (EOS) was used for the hydrostatic part of the stress, and the Johnson-Cook strain sensitive plasticity model, already used by many authors [8-11] for problems where strain rates vary over a large range, was used. With $\varepsilon_{\mathrm{p}}$ as the equivalent plastic strain, the Von Mises flow stress, according to the Johnson-Cook model, is given by

$$
\begin{aligned}
\sigma= & \left(\sigma_{\mathrm{Y}}+K \varepsilon_{\mathrm{p}}^{n}\right) \cdot\left[1+C \cdot \operatorname{Ln}\left(\frac{\dot{\varepsilon}}{\dot{\varepsilon}_{0}}\right)\right] \\
& \cdot\left[1-\left(\frac{T-T_{0}}{T_{\text {melt }}-T_{0}}\right)^{m}\right]
\end{aligned}
$$

where $\sigma_{\mathrm{Y}}, K, C, n$ and $m$ are material constants: $\sigma_{\mathrm{Y}}$ is the yield stress, $K$ and $n$ are the work-hardening modulus and coefficient, $C$ is the strain-rate sensitivity, $T_{\text {melt }}$ is the fusion temperature $(900 \mathrm{~K})$ and $T_{0}$ is the reference temperature (298 K).

The corresponding Johnson-Cook coefficients were selected using the stress-strain static curves $\left(\sigma_{\mathrm{Y}}, K, n\right)$, and the $C$ strain-rate sensitivity factor was experimentally identified using VISAR measurements of HEL values (see section 3.1). Mechanical and physical data used for the calculation are summarized in table 3. A Fortran subroutine was used (*VDLOAD type) to generate non-uniform spatial and temporal loadings $P=f(x, y, t)$ and to precisely locate the impact position. The $P(t)$ profile (figure 4(a)) was determined using VISAR tests on thin Al foils, combined with simulations. Similar to previous papers [10], the $P=f(x, y)$ distribution 

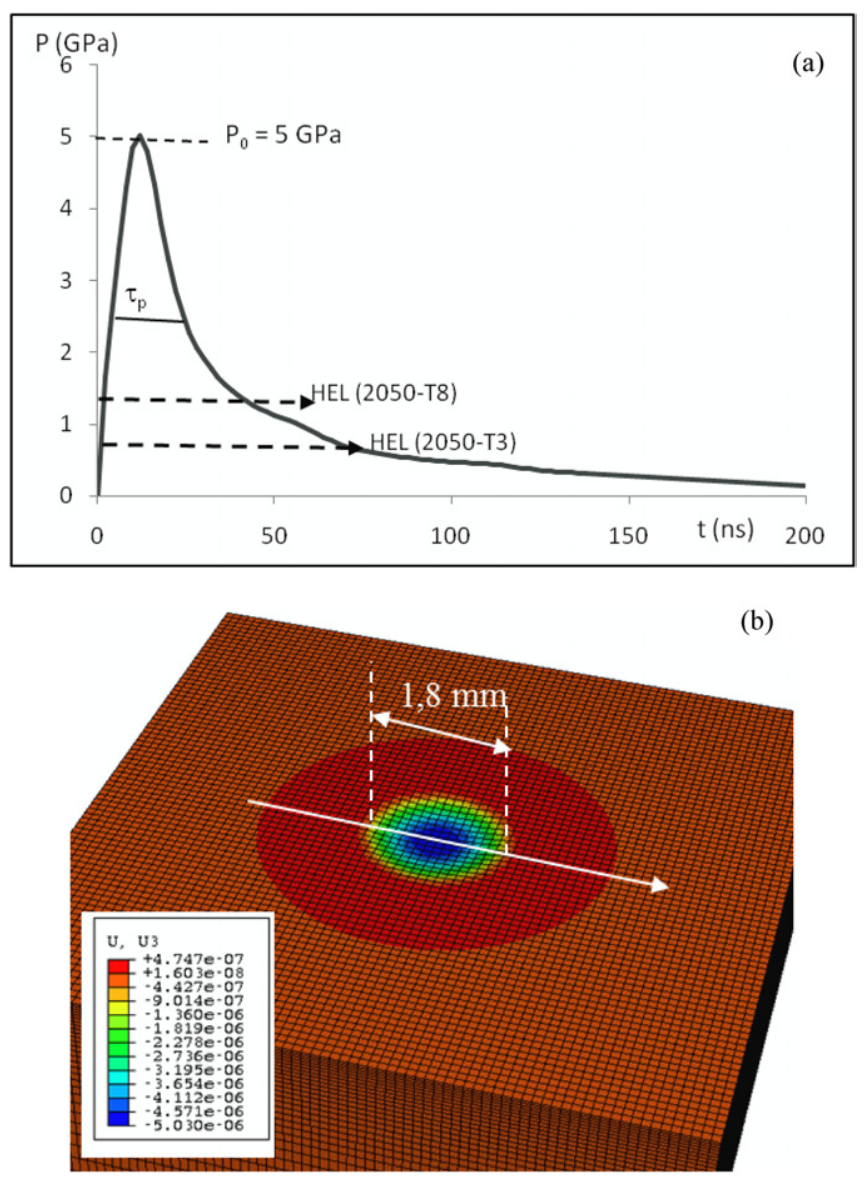

Figure 4. (a) $P=f(t)$ pressure profile identified by VISAR experiments and Abaqus simulations on thin pure aluminum foils (b) Detailed view of the simulation of a $5 \mathrm{GPa}$ impact on 2050-T8 $\left(u_{3}\right.$ values in $\left.\mathrm{m}\right)$.

was adjusted to provide an optimum fitting with experimental surface deformations $u_{3}=f(x)$ for a given laser intensity $I_{0}$ $\left(\mathrm{W} \mathrm{cm}^{-2}\right)$.

\section{Results}

\subsection{Experimental versus numerical shock wave profiles}

For each material condition (T3, T8 or T3 + FSW), three to four VISAR tests were carried out on different foil thicknesses, obtained by precision saw-cutting. An example of the back free velocity profile obtained behind a $740 \mu \mathrm{m}$-thick 2050-T8 foil submitted to a $5 \mathrm{GW} \mathrm{cm}^{-2}$ impact is shown in figure 5 . On such a velocity profile, the peak velocity can be directly related to the pressure amplitude $740 \mu \mathrm{m}$ below the surface (equation (2)), whereas the inflexion evidenced in the shock rise time is known as the elastic precursor (equation (3)), and corresponds to the elastic-plastic transition under uniaxial shock loading. The following comments can be made from figure 5 .

- First, the peak velocity $\left(225 \mathrm{~m} \mathrm{~s}^{-1}=1.75 \mathrm{GPa}\right.$ stress $)$ is reproduced well by a simulation for a $P_{0}=$ 3.5 GPa impact. This afterwards confirms the ability of the pressure $P_{0}$ versus power density $I_{0}$ empirical dependence, $P_{0}(\mathrm{GPa})=1.6 \cdot \sqrt{I_{0}}\left(\mathrm{GW} \mathrm{cm}^{-2}\right)$, to predict confined plasma pressures.
- Second, a $122 \mathrm{~m} \mathrm{~s}^{-1}$ velocity level is evidenced at the elastic-plastic transition, which corresponds to a $1.04 \mathrm{GPa}$ yield stress under planar laser-shock loading (or HEL (equation (3))).

- Third, the main difference between experimental and numerical data is visible on the release part of the shock wave (after the peak pressure), where the simulation tends to overestimate the $2 \mathrm{D}$ effects, tending to promote the generation of a tensile stress state after $t=200 \mathrm{~ns}$.

The determination of the HEL allows us to estimate the dynamic yield stress (equation (3)), and in turn the strain-rate sensitivity factor $C$ as input data for the constitutive JohnsonCook equation.

On 2050-T8, considering four different VISAR measurements (table 4), we obtain an average HEL value of $1.03 \pm 0.06 \mathrm{GPa}$, and, using equation (3), a dynamic yield stress value $\sigma_{\mathrm{Y}}^{\text {dyn }}$ equal to $0.53 \mathrm{GPa}$. This indicates a very low strainrate sensitivity coefficient $C=0.002$ (for $\sigma_{\mathrm{Y}}=0.5 \mathrm{GPa}$ ). However, the shape of the elastic precursor (rather steep on the VISAR profile) is not really well represented by the FEM simulation of the shock waves, where the elastic-plastic transition exhibits a near-plateau inflexion (figure 5).

On an $850 \mu \mathrm{m}$ thick 2050-T3 foil (figure 6), numerical and VISAR-determined peak velocities are also in relatively good agreement $\left(244 \mathrm{~m} \mathrm{~s}^{-1}\right.$ versus $\left.232 \mathrm{~m} \mathrm{~s}^{-1}\right)$. Simulations also confirm the maximum applied pressure $P_{0}(=3.5 \mathrm{GPa}$ at $5 \mathrm{GW} \mathrm{cm}^{-2}$ ), and an HEL of 0.6 GPa is obtained. Considering the average values (table 4 ), a value of $0.54 \pm 0.05 \mathrm{GPa}$ is found for 2050-T3, corresponding to a dynamic yield stress of $0.29 \mathrm{GPa}$, and nearly no strain-rate sensitivity $(C \approx 0)$. Consequently, the two alloys exhibit approximately the same (low) strain-rate sensitivity under laser-shock loading.

Similar tests were carried out on thin foils extracted from 2050-T3 FSW nuggets (figure 3(b)). Behind a $840 \mu \mathrm{m}$-thick foil (figure 7), an HEL value of $0.58 \mathrm{GPa}$ is obtained, and averaged values indicate $0.56 \pm 0.06 \mathrm{GPa}$. This will be further discussed in section 3.3.

Therefore, using VISAR measurements and $P=f(t)$ profiles (figure 3), HEL values could be determined with a $10 \%$ maximum variation (table 4 ), and could be used as input data in the numerical simulation of surface deformations.

\subsection{Experimental versus numerical laser-induced surface deformations}

Considering a single $1.5 \mathrm{~mm}$ impact ( $r_{0}=0.75 \mathrm{~mm}$, figure 8) impacted at $8 \mathrm{GW} \mathrm{cm}^{-2}$, and a maximum available impact pressure $P_{0}=5 \mathrm{GPa}$ in the $10-30 \mathrm{~ns}$ laser pulse range at $\lambda=$ $0.532 \mu \mathrm{m}$ [5], the best agreement with experience (figure 9) was found for a near-spherical spatial distribution of pressure (equation (5)). The corresponding maximum deformation $u_{33}$ induced by a single impact is shown to be approximately $-10 \mu \mathrm{m}$.

$$
P=P_{0} \cdot \sqrt{1-\frac{x^{2}}{r_{0}^{2}}},
$$

where $x$ is the radial distance and $r_{0}$ is the impact radius. 
Table 3. Physical and mechanical properties of $2050 \mathrm{Al}-\mathrm{Cu}-\mathrm{Li}$ aluminum alloy.

\begin{tabular}{llllllllll}
\hline & $\rho\left(\mathrm{kg} \mathrm{m}^{-3}\right)$ & $E(\mathrm{GPa})$ & $v$ & $\sigma_{\mathrm{Y}}(\mathrm{GPa})$ & $K(\mathrm{GPa})$ & $n$ & $H(\mathrm{GPa})^{\mathrm{a}}$ & $C_{0}\left(\mathrm{~m} \mathrm{~s}^{-1}\right)$ & $C_{\mathrm{el}}\left(\mathrm{m} \mathrm{s}^{-1}\right)$ \\
\hline 2050-T8 & 2700 & 76 & 0.33 & 0.5 & 0.2 & 0.5 & 1.75 & 5390 & 6200 \\
2050-T3 & 2700 & 74 & 0.33 & 0.29 & 0.48 & 0.3 & 1.3 & 5390 & 6200 \\
2050-T3 (FSW) & 2700 & 74 & 0.33 & $?$ & $?$ & $?$ & 1.28 (upper) & 5390 & 6200 \\
& & & & & & & 1.13 (lower) & & \\
\hline
\end{tabular}

${ }^{a}$ Determined by Vickers tests with a $25 \mathrm{~g}$ load.

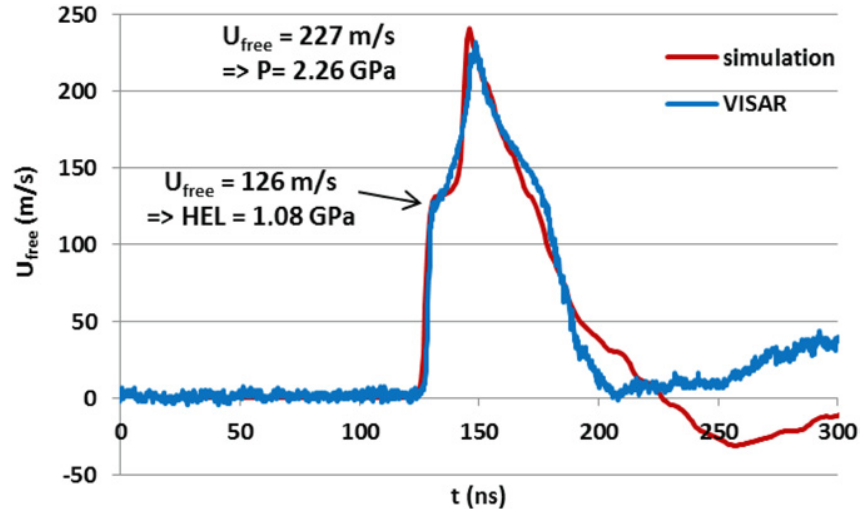

Figure 5. VISAR velocity profile behind a $0.74 \mathrm{~mm}$ thick $2050-\mathrm{T} 8$ foil-experimental versus numerical data $\left(I_{0}=5 \mathrm{GW} \mathrm{cm}^{-2}\right.$, $P_{0}=3.8 \mathrm{GPa}$ is the applied pressure for the simulation).

Table 4. Summary of VISAR experiments on 2050 foils (average HEL values $=1.03 \pm 0.05 \mathrm{GPa}(2050-\mathrm{T} 8), 0.54 \pm 0.05 \mathrm{GPa}$ (2050-T3), $0.56 \pm 0.06 \mathrm{GPa}(2050-\mathrm{T} 3 \mathrm{FSW})$ ).

\begin{tabular}{llllll}
\hline \multirow{2}{*}{ Material } & $\begin{array}{l}\text { Foil } \\
\text { thickness } \\
(\mathrm{mm})\end{array}$ & $\begin{array}{l}I_{0} \\
\left(\mathrm{GW} \mathrm{cm}^{-2}\right)\end{array}$ & $\begin{array}{l}P^{\mathrm{a}} \\
(\mathrm{GPa})\end{array}$ & $\begin{array}{l}U_{\mathrm{HEL}} \\
\left(\mathrm{m} \mathrm{s}^{-1}\right)\end{array}$ & $\begin{array}{l}\mathrm{HEL} \\
(\mathrm{GPa})\end{array}$ \\
\hline $2050-\mathrm{T} 8$ & 0.74 & 5 & 3.5 & 126 & 1.08 \\
& 0.74 & 4.9 & 3.5 & 125 & 1.07 \\
& 0.38 & 4.8 & 3.4 & 120 & 1.03 \\
$2050-\mathrm{T} 3$ & 1.24 & 5.2 & 3.6 & 109 & 0.98 \\
& 0.85 & 4.9 & 3.5 & 78 & 0.67 \\
$2050-\mathrm{T} 3$ (FSW) & 0.6 & 4.8 & 3.4 & 55 & 0.5 \\
& 0.8 & 5.5 & 3.7 & 58 & 0.5 \\
& 0.84 & 6 & 3.9 & 73 & 0.63 \\
& 0.84 & 5.5 & 3.4 & 66 & 0.57 \\
& 1.2 & 5.5 & 3.7 & 57 & 0.51 \\
& & & 3.7 & 62 & 0.54 \\
\hline
\end{tabular}

${ }^{\text {a }} P$ - estimated pressure using experimental data from [5].

Using this pressure distribution, a systematic comparison was carried out between experimental and numerical surface deformations considering the following:

- the influence of laser intensity $I_{0}\left(\mathrm{GW} \mathrm{cm}^{-2}\right)$ and the resulting impact pressure $P_{0}(\mathrm{GPa})$;

- the influence of repeated impacts (between $N=1$ and $N=6$ ) at the same location;

- the influence of the target material (2050-T8, 2050-T3, 2050-T3 + FSW).

Analytically, the global surface deformations $e(\mu \mathrm{m})$ can also be approximated by considering the integral value of particle velocity profiles $U(t)$ above the HEL of the impacted material (equation (6)). This confirms that long pressure pulses

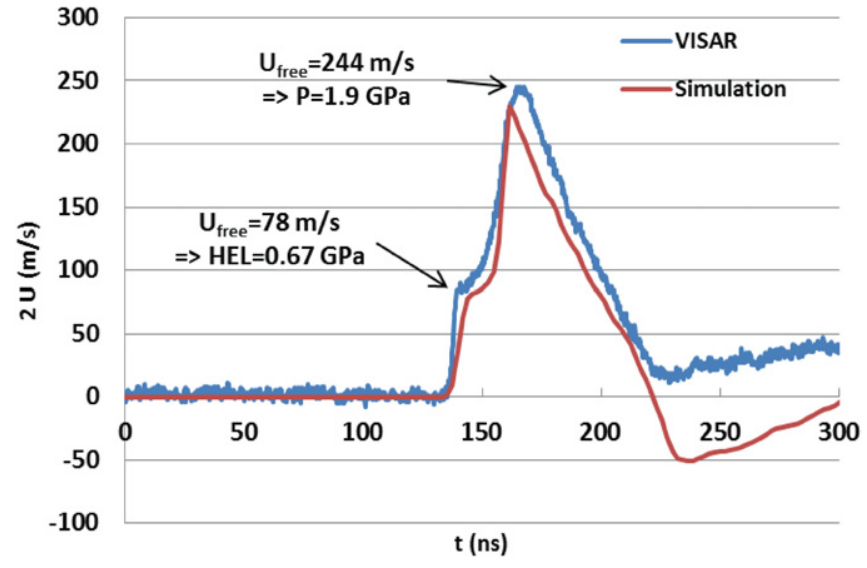

Figure 6. VISAR velocity profile behind a $0.85 \mathrm{~mm}$ thick $2050-\mathrm{T} 3$ foil- experimental versus numerical data $\left(I_{0}=4.9 \mathrm{GW} \mathrm{cm}^{-2}\right.$, $P_{0}=3.5 \mathrm{GPa}$ is applied on the front surface).

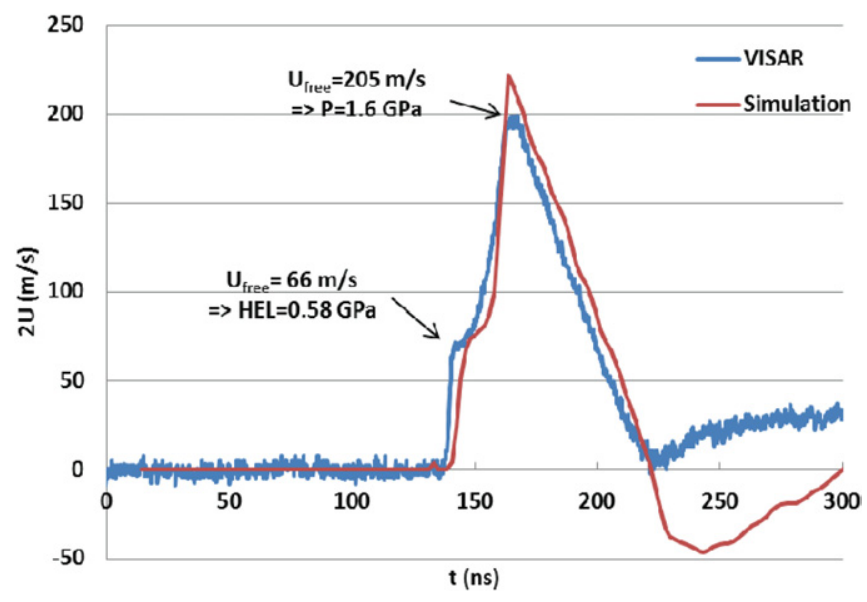

Figure 7. VISAR velocity profile on a $0.84 \mathrm{~mm}$ thick $2050-\mathrm{T} 3$ (FSW) foil-experimental versus numerical data ( $I_{0}=4.5 \mathrm{GW} \mathrm{cm}^{-2}, P_{0}=3.4 \mathrm{GPa}$ is applied on the front surface).

are expected to perform deeper laser indents:

$$
e=\int_{0}^{\infty}\left(U(t)-U_{\mathrm{HEL}}\right) \cdot \mathrm{d} t .
$$

Experimental determinations indicate a polynomial $e=$ $f\left(P_{0}^{2}\right)$ tendency for surface deformations (figure 10), which is confirmed by numerical simulations (figure 11) for the two heat treatments $\mathrm{T} 3$ and $\mathrm{T} 8$.

The $e=f\left(P_{0}\right)$ curves could also be used for estimating the HEL values (figure 11), but was not considered as the optimum method compared with VISAR identifications, due to the polynomial shape of the $e=f\left(P_{0}\right)$ curves, where the 


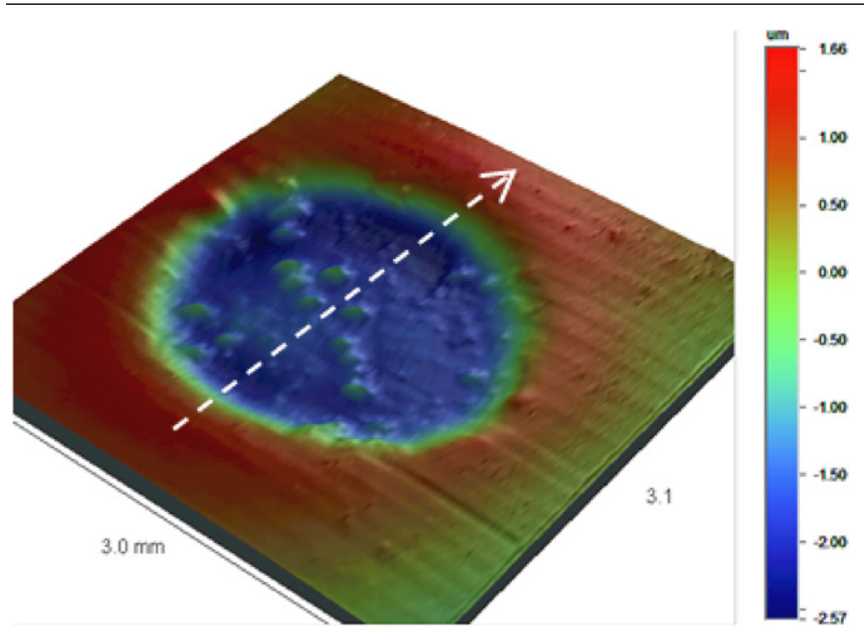

Figure 8. 3D map of a single laser impact ( $1.6 \mathrm{~mm}$ diameter) on a 2050-T8 aluminum alloy $\left(5.5 \mathrm{GW} \mathrm{cm}^{-2} \approx 3.8 \mathrm{GPa}\right)$.

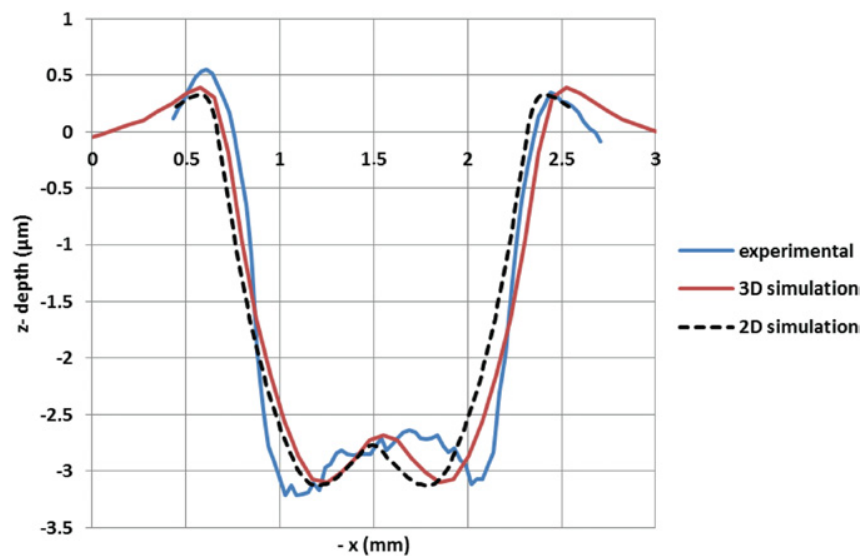

Figure 9. Surface deformation induced by a single $1.6 \mathrm{~mm}$ laser impact on 2050-T8 - experimental versus numerical data $\left(I_{0}=5.5 \mathrm{GW} \mathrm{cm}^{-2}\right)-2 \mathrm{D}$ and $3 \mathrm{D}$ simulations using a spherical $P=f(x, y)$ distribution with $P_{0}=3.8 \mathrm{GPa}$.

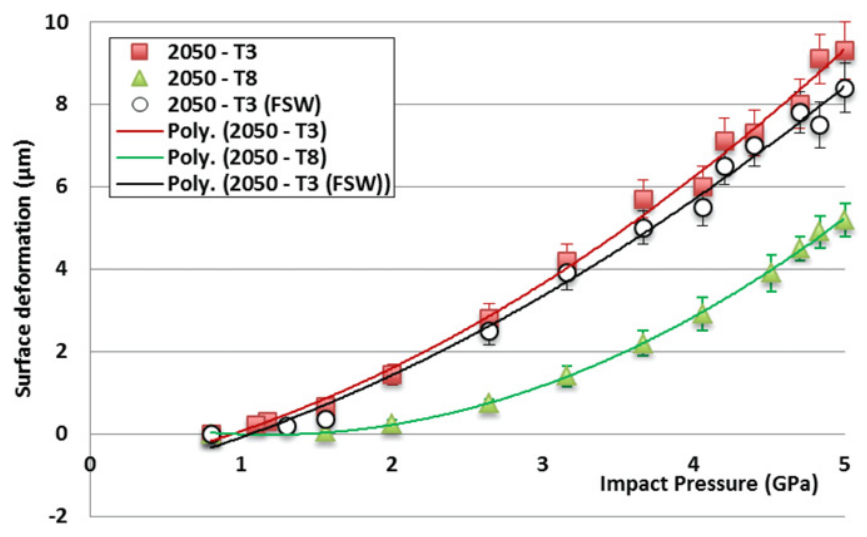

Figure 10. Experimentally determined surface deformations versus impact pressure for 2050-T3, 2050-T8 and 2050-T3 (FSW) alloys. Curves follow approximately a polynomial $e^{2}=f\left(P_{0}\right)$ dependence.

error bar is high on HEL determination. This explains why rather large differences exist between VISAR-determined HEL values and experimental thresholds for surface deformations: for instance $1.02 \mathrm{GPa}$ versus $1.4 \mathrm{GPa}$ on 2050-T8.

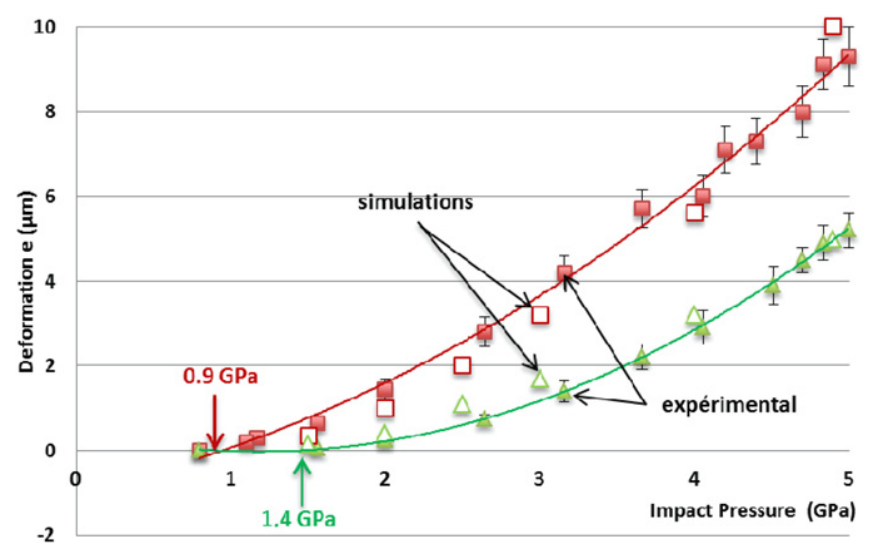

Figure 11. Comparison between experimental and simulated $e=f\left(P_{0}\right)$ values. Extrapolating the $e=f\left(P_{0}\right)$ curves using $e^{2}=f\left(P_{0}\right)$ polynomial functions; HEL values were estimated to be approximately $1.4 \mathrm{GPa}$ for $2050-\mathrm{T} 8$ and $0.9 \mathrm{GPa}$ for 2050-T3.

(a)

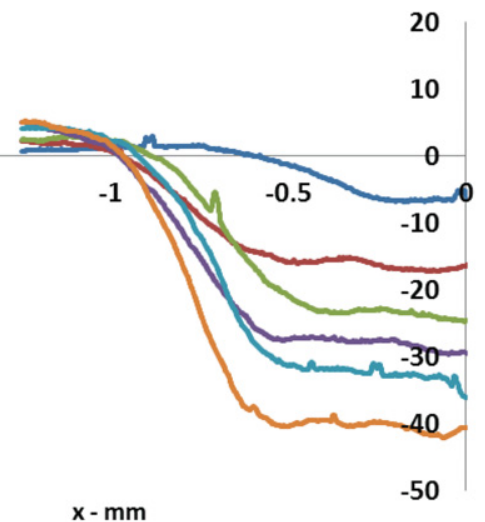

(b)

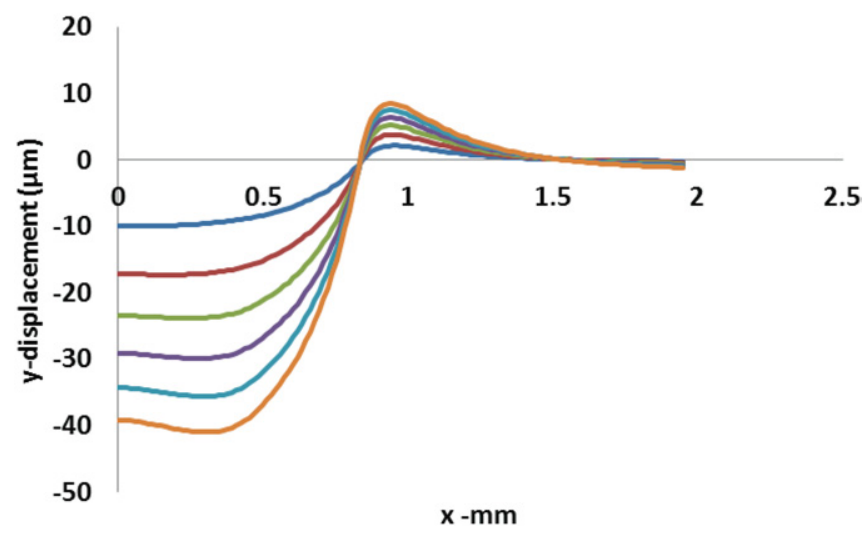

Figure 12. Surface deformations induced by 1-6 laser impacts of diameter $d=1.6 \mathrm{~mm}$ at $I_{0}=6.5 \mathrm{GW} \mathrm{cm}^{-2}$ on 2050-T3: (a) experimental data, $(b)$ simulated profiles with the $2 \mathrm{D}$ model $\left(P_{0}=4.1 \mathrm{GPa}\right)$.

As the LSP process generates cyclic deformations on the metal surface, due to impact overlaps, the analysis of surface deformations produced by cumulative laser impacts is of primary importance. In figure 12, a comparison between experimental and simulated surface deformations is shown for a 2050-T3 alloy with $I_{0}=6.5 \mathrm{GW} \mathrm{cm}^{-2}\left(P_{0}=4.1 \mathrm{GPa}\right.$ is the estimated pressure), and 1-6 impacts at the same location. The experimental depth versus impact number $N$ 


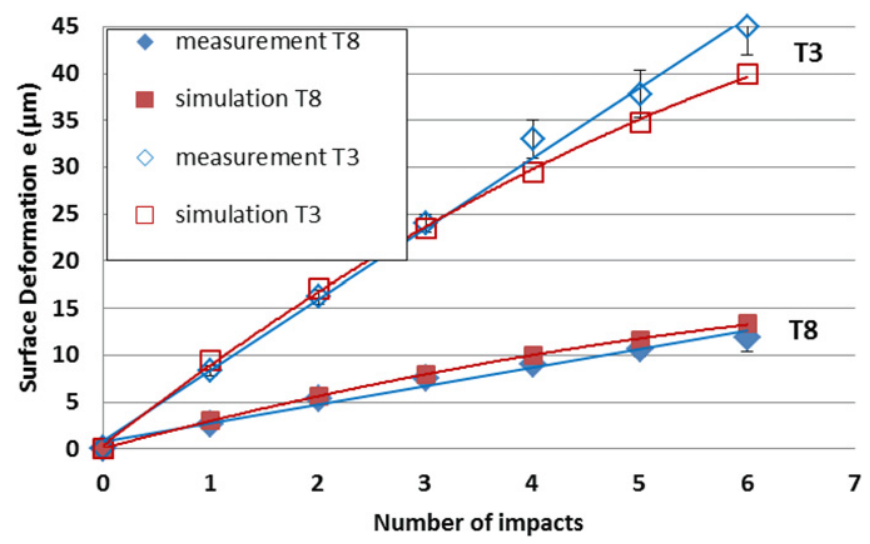

Figure 13. Surface deformations induced by 1-6 laser impacts at $I_{0}=6 \mathrm{GW} \mathrm{cm}^{-2}\left(P_{0}=4 \mathrm{GPa}\right)$ on 2050-T8 alloy (experimental values versus numerical calculations).

curves are different for 2050-T3 and T8 (figure 13): (1) on 2050-T8, a decrease in depth per impact with the number of impact loadings $N$ is found (polynomial regression), (2) on 2050-T3, the depth per impact exhibits a constant value $=$ $7.5 \mu \mathrm{m} / \mathrm{impact}$. Even with the use of specific $C$ parameters obtained from VISAR experiments (see section 3.1), good agreement with simulation could not be found on 2050-T3. This seems to indicate that the 2050-T3 alloy exhibits pure elastic-plastic behaviour under laser-shock loading $(K=0$ in the Johnson-Cook equation), whereas 2050-T8 maintains a certain degree of work-hardenability at a very high strain rate.

\subsection{Behaviour of a friction-stir nugget under laser-shock loading}

A combination of VISAR analysis and surface deformation measurements allows the identification of the mechanical properties of a friction-stir weld, focusing more specifically on the nugget central part. If we consider Vickers hardness measurements (table 3), the FSW nuggets exhibit relatively lower values than the as-thermal-treated (T3) material. Moreover, the upper part of the FSW nuggets is 10\% harder than the lower part. Such a decrease in hardness is usually attributed to a modification of the precipitate sub-structure (dissolution or coarsening of $\mathrm{T} 1$ particles), due to the semisolid metal processing.

If we now analyse VISAR velocity profiles and surface deformations versus impact pressures, we can make the following statements:

(1) the average HEL value is slightly higher on T3 (FSW) than on $\mathrm{T} 3$ ( $0.56 \mathrm{GPa}$ versus $0.54 \mathrm{GPa}$ - table 4 );

(2) surface deformations are 5\% smaller on $\mathrm{T} 3+\mathrm{FSW}$ samples than on T3 samples (figure 10).

This confirms that VISAR determination of elastic precursors and residual depths of laser indents are in good agreement. However, the FSW samples exhibit lower hardness values than the as-rolled T3 samples (table 1). As the HV values traduce the elastic limit under static conditions, this tends to indicate higher strain-rate sensitivity (higher $C$ values) on the FSW samples, mainly due to a grain refinement effect, and despite precipitate dissolution or coarsening in semi-solid regime.

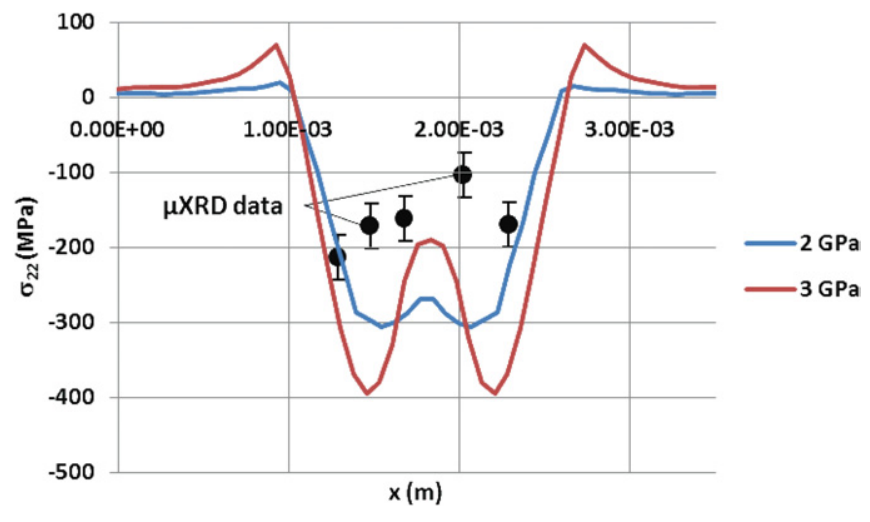

Figure 14. Residual stresses induced by a single laser impact at $I_{0}=3.5 \mathrm{GW} \mathrm{cm}^{-2}(2050-\mathrm{T} 8)$ - experiments versus simulation at impact pressures $P_{0}=2$ and $3 \mathrm{GPa}$.

\subsection{Determination of residual stresses on a single $1.5 \mathrm{~mm}$ impact}

In this section, we consider the pressure dependence of residual stresses for a single impact, together with an experimental validation using a $\mu$ XRD technique, and the classical $2 \theta=$ $f\left(\sin ^{2} \Psi\right)$ method. A $50 \mu \mathrm{m}$ x-ray collimator was used at ICB-Dijon for analysing stress distributions, corresponding, after beam divergence, to a $100 \mu \mathrm{m}$ XRD spot on the metal.

Despite the apparently large grain sizes, the use of a classical $\sin ^{2} \Psi$ approach was shown to be possible with a $100 \mu \mathrm{m}$ XRD spot, due to the presence of partially recrystallized areas in Al grains (figure 3(a)), which acted as sub-diffracting domains. Another important point is that the EBSD and XRD techniques did not probe the same depth (less than $0.1 \mu \mathrm{m}$ for EBSD and 6-9 $\mu \mathrm{m}$ for XRD). Consequently, a much larger number of diffracting grains are expected to have contributed to the residual stress determination than revealed by figure $3(a)$. The corresponding grain size in the direction perpendicular to the surface was estimated to be $1 \mu \mathrm{m}$.

Simulations indicate that the stress drop at the centre of circular impacts seems to be promoted by the use of high pressures: a pressure of $3 \mathrm{GPa}$ provides a less homogeneous stress field than $2 \mathrm{GPa}$ (figure 14). Considering shock wave behaviour, this result is attributed to enhanced effects of lateral release waves, generated at the edges of circular impacts, and focusing at the centre. A comparison between experimental and simulated residual stress values indicates an overestimation of $100 \mathrm{MPa}$ for the residual stress amplitude $(-300 \mathrm{MPa}$ versus $-200 \mathrm{MPa})$, even at an impact pressure of $2 \mathrm{GPa}$.

In the numerical work, we also tried to use different applied pressure distributions $P=f(x, y)$ (for instance quasiexponential-like $P=P_{0} \cdot \exp \left(-2 x^{n} / r^{n}\right)$ to limit the local pressure gradients at the spot edge, and limit the resulting lateral release waves provoking central stress drops. However, even if such attempts were shown to slightly homogenize the residual stress field, they failed to reproduce surface deformations and maximum residual stress levels.

Different factors may explain why the experimental to numerical comparison is not that satisfactory on one impact: (1) the $\mu$ XRD patterns are mostly obtained inside grains on very small diffracting crystallites that may not be fully 
representative of the global aluminum diffraction constants, (2) the experimental residual stress field is overwhelmed by the central stress drop [7], which is more pronounced and extended than numerically predicted, (3) the Johnson-Cook model fails to reproduce the residual stress formation, possibly due to an underestimation of thermal effects during loading.

\section{Summary and discussion}

VISAR velocity measurements and surface deformations induced by laser-shock loading were both used to identify the high strain-rate behaviour of 2050-T3, 2050-T8 and 2050-T3 (FSW) alloys. A combination of experiments and numerical simulations was used, and the elastic limit under planar shock loading (HEL) could be determined, together with the evolution of indent depths versus pressure $P_{0}$ and impact number $N$.

Different behaviours are observed: (1) 2050-T3 exhibits a near-zero strain-rate sensitivity and no work hardening, (2) 2050-T8 exhibits a low strain-rate sensitivity $(C=0.002)$ and a moderate work hardening, (3) the FSW samples exhibit a higher strain-rate sensitivity.

Initially, the T3 + FSW samples are mostly hardened by the interaction between grain boundaries and dislocations, whereas the T3 and T8 samples are precipitation-hardened. This seems to reveal that aluminum alloys hardened by a Hall-Petch-like effect (grain refinement) are more strain-rate sensitive than precipitation-hardened alloys. However, a more detailed metallurgical analysis of the influence of grain boundaries and/or nano-scale precipitate distribution versus plastic deformation and dislocation motion at ultra-high strain rate $\left(10^{6} \mathrm{~s}^{-1}\right)$ should provide us with many useful explanations to clarify this point.

\section{Conclusions}

Surface deformations induced by single and repeated laser impacts on a 2050 alloy with different microstructures generated by different heat treatments or by a FSW process were investigated by experimental and numerical means.

Rather good agreement was found between experimental and numerical data, using the Johnson-Cook constitutive law. Low strain-rate sensitivity coefficients $C$ of the JohnsonCook model were identified, through the identification of HELs by VISAR velocity measurements. This allowed the calculation of surface deformations versus impact pressure and repeated impacts. Such a simple and new approach combining the analysis of surface deformations and shock wave propagation is shown to be an efficient method for analysing materials' behaviour under laser-shock loading, and identifying parameters of constitutive laws. However, on the 2050-T8 alloy, it was not shown to be sufficient for accurately predicting residual stress fields.

\section{Acknowledgment}

Part of this work was supported by the French ANR within the framework of CAPSUL project (http://capsul.gerailp.fr/tiki/ tiki-index.php).

\section{References}

[1] Clauer A H, Holbrook J H and Fairand B P 1981 Shock Waves and High-strain-rate Phenomena in Metals Concepts and Applications (New York: Plenum) pp 675-702

[2] Azer M N and Scheidt D 2004 The influence of spot overlap and laser fluence on the high cycle fatigue (HCF) strength of aircraft engine blades Proc. ICALEO'2004 Conf. (San Francisco, $C A$ )

[3] Sano Y, Yoda M and Mukai N 2000 Residual stress improvement mechanism on metal material by underwater laser irradiation J. At. Energy Soc. Japan 42 567-73

[4] Fabbro R, Fournier J, Ballard P, Devaux D and Virmont J 1990 Physical study of laser produced plasma in confined geometry J. Appl. Phys. 68 775-84

[5] Berthe L, Fabbro R, Peyre P, Tollier L and Bartnicki E 1997 Shock waves from a water-confined laser-generated plasma J. Appl. Phys. 82 3550-8

[6] Barker L M and Hollenbach R E 1972 Laser interferometer for measuring high velocities of any reflecting surfaces $J$. Appl. Phys. 43 4669-78

[7] Ballard P 1991 Contraintes résiduelles induites par impact rapide - application au choc-laser Doctoral Thesis Ecole Polytechnique, France

[8] Braisted W and Brockman R 1999 Finite element simulation of laser shock peening Int. J. Fatigue 21 719-24

[9] Ding K and Ye L 2003 Three-dimensional dynamic finite element analysis of multiple laser shock peening processes Surf. Eng. 19 351-8

[10] Peyre P, Sollier A, Berthe L, Bartnicki E, Fabbro R, Chaieb I and Braham C 2003 FEM simulation of residual stresses induced by laser Peening EPJ Appl. Phys. 23 83-8

[11] Ocana J L, Morales M and Molpeceres C 2004 Numerical simulation of surface deformation and residual stresses fields in laser shock processing experiments Appl. Surf. Sci. 238242

[12] Coratella S et al 2011 Use of a simplified eigenstrain method for predicting LSP-induced residual stresses 3rd Laser Shock Peening Conf. (LSP3) (Osaka, Japan)

[13] Rouleau B, Peyre P, Baudin T,Breuils J and Pelletier H 2011 Characterization at a local scale of a laser-shock peened aluminum alloy surface Appl. Surf. Sci. 257 7195-203

[14] Viejo F, Coy A E, Garcia-Garcia F J, Merino M C, Liu Z, Skeldon P and Thompson G E 2010 Enhanced performance of the AA2050-T8 aluminium alloy following excimer laser surface melting and anodising processes Thin Solid Films $5182722-31$

[15] Viejo F, Coy A E, Garcia-Garcia F J, Liu Z, Skeldon P and Thompson GE 2010 Relationship between microstructure and corrosion performance of AA2050-T8 aluminium alloy after excimer laser surface melting Corros. Sci. 52 2179-87

[16] Contrepoix Q 2010 Texture et anisotropie du comportement mécanique après laminage à chaud d'un alliage léger $\mathrm{Al}-\mathrm{Cu}-\mathrm{Li}$ pour l'aéronautique $\mathrm{PhD}$ Doctorate Ecole des Mines de St Etienne, France

[17] Lequeu P, Smith K P and Daniélou A 2009 Aluminum-Copper-Lithium Alloy 2050 developed For medium to thick plate J. Mater. Eng. Perform. $19841-7$

[18] Hatamleh O, Singh Preet M and Garmestani H 2009 Corrosion susceptibility of peened friction stir welded 7075 aluminum alloy joints Corros. Sci. 51 135-43

[19] Hatamleh O, Mishra R S and Oliveras O 2009 Peening effects on mechanical properties in friction stir welded AA2195 at elevated and cryogenic temperatures Mater. Des. 30 3165-73

[20] Peyre P, Berthe L, Scherpereel X and Fabbro R 1998 Experimental study of laser-driven shock waves in stainless steels J. Appl. Phys. 84 5985-92 